Fanum

Sociológico

\section{Forum Sociológico}

Série II

$18 \mid 2008$

Explorando os interstícios urbanos

\title{
Prácticas creativas y de intervención: el Rap político en la Cova da Moura, Lisboa
}

\section{Edurne de Juan}

\section{(2) OpenEdition \\ 12 Journals}

\section{Edição electrónica}

URL: https://journals.openedition.org/sociologico/266

DOI: 10.4000/sociologico.266

ISSN: 2182-7427

\section{Editora}

CICS.NOVA - Centro Interdisciplinar de Ciências Sociais da Universidade Nova de Lisboa

\section{Edição impressa}

Data de publição: 1 junho 2008

Paginação: 59-66

ISSN: 0872-8380

\section{Refêrencia eletrónica}

Edurne de Juan, «Prácticas creativas y de intervención: el Rap político en la Cova da Moura, Lisboa», Forum Sociológico [Online], 18 | 2008, posto online no dia 03 dezembro 2012, consultado o 30 março 2022. URL: http://journals.openedition.org/sociologico/266 ; DOI: https://doi.org/10.4000/sociologico. 266

Este documento foi criado de forma automática no dia 30 março 2022.

(c) CICS.NOVA 


\title{
Prácticas creativas y de intervención: el Rap político en la Cova da Moura, Lisboa
}

\author{
Edurne de Juan
}

\section{Practicas creativas y de intervención: el rap político en la Cova da Moura'}

1 Cuando hace unos años llegué a la Cova da Moura $^{2}$ por primera vez con la idea de hacer un trabajo etnográfico sobre el rap ${ }^{3}$, en un principio tuve la impresión, algo inocente o inexperta, de estar delante de una forma de expresión autónoma y compacta: un grupo de jóvenes que creí que podía denominar, y de hecho así lo hice en uno de los primeros trabajos, bajo la etiqueta de "los jóvenes Mc de origen caboverdiano". Ahora, sopesando un poco esta breve trayectoria de investigación, y tras reflexionar sobre esta idea pienso que la expresión referida a los orígenes no sea la más adecuada para representar a este grupo de jóvenes. Considero que estas categorías que construimos para representar al otro son un poco complicadas ya que limitan nuestra mirada. En este sentido, podemos ver una minoría étnica como una minoría. Nada nuevo va a salir de ahí, siguiendo con la representación predefinida: "los negros", "los hijos de emigrantes" etc. Por eso, en nuestro caso, en vez de verlos como una minoría social a priori, como "los jóvenes de origen caboverdiano" o "los descendientes de inmigrantes africanos", optamos por estudiar un grupo, sus relaciones, y el sentido de sus relaciones y de las prácticas, es decir, el rap. Así, nos propusimos buscar el sentido de la práctica, en sus múltiples relaciones, allí mismo donde ellas ocurren, a partir del punto de vista del otro sobre sus propias prácticas. Para ello, a través del trabajo de campo prolongado, hemos tratado, de buscar el sentido de forma contextual, trabajando con las prácticas de sentido de este grupo de jóvenes. Queremos establecer un diálogo con el significado de la vida del otro, el sentido que el grupo da a su propia realidad, no un diálogo con el significado que nuestra teoría atribuye a la vida de este grupo. En este sentido, el 
trabajo etnográfico nos proporciona la posibilidad de mantener un diálogo profundo que se convierte en un aprendizaje continuo. Intentamos comprender su manera de sentir su identidad colectiva, realizando una interpretación de una interpretación, y es ahí donde creemos que se situa la Antropología.

Pensar sobre estos jóvenes únicamente bajo la perspectiva de su origen sería limitar considerablemente nuestra mirada ya que las referencias y los matices son inconmensurables y van mucho más allá de sus orígenes. Las referencias entre el nivel local y el nivel global se funden creando una multiplicidad de raíces y pertenencias. Estamos ante un nuevo escenario global. El vínculo entre la cultura y el espacio ya no es del mismo tipo. Las conexiones transnacionales son cada vez más presentes y las hibridaciones, consustanciales a la sociedad. En un mismo territorio, encontramos personas que vienen de distintos lugares. $\mathrm{Y}$ al flujo de personas hemos de sumarle además una intensa y rápida circulación de ideas, símbolos y mercancías. Se han creado nuevas redes de relaciones transnacionales y modos de vida globalizados, debiendo a partir dela ajustarnos a estos procesos, replanteando la práctica y metodología antropológicas, desestimando la territorialidad y las ideas absorbidas de la cultura localizada y comprometiéndonos a pensar en el dinamismo y movilidad de las culturas. Siguiendo a Hannerz:

"A medida que las personas se desplazan con sus significados y a medida que los significados encuentran formas de desplazarse aunque las personas no se muevan, los territorios ya no pueden ser contenedores de una cultura. Incluso si aceptamos que la cultura se adquiere y se organiza socialmente, suponer que se distribuye de forma homogénea dentro de una colectividad se convierte en algo problemático cuando vemos las diferentes experiencias y biografías de sus miembros." (Hannerz; 1998: 23-24)

3 Esta nueva diversidad cultural pone en cuestión el concepto de cultura y obliga a abandonar la idea en la que se sustentaba el trabajo de campo clásico, es decir, la idea de la cultura localizada, la idea de unos valores culturales materializados en un espacio en concreto que se absorben y se comparten por un grupo homogéneamente. En la actualidad, la cultura ha atravesado los límites tradicionales de un espacio delimitado. Es así como nos aproximamos a una nueva manera de entender la cultura, en la que se piensa en flujos intensos y en profundas hibridaciones.

Las investigaciones clásicas, se fundamentaban en la creencia en la discontinuidad cultural. Es decir, se confería unidad cultural a una unidad territorial que se pensaba infranqueable. Se estudiaban los grupos de forma aislada y territorializados en un espacio geográfico determinado. De esta manera fue cimentándo-se una asociación naturalizada entre la cultura y el espacio, entre un grupo culturalmente homogéneo delimitado en un espacio. Sólo a partir de los años sesenta y setenta se producirá un primer cambio en los planteamientos antropológicos, dejando en evidencia la relación e influencia existente entre los diferentes grupos.

"Las sociedades humanas jamás están solas; cuando más nos parece que están separadas descubrimos que forman grupos o conjuntos... que mantienen entre sí contactos muy estrechos. $\mathrm{Y}$, junto a las diferencias debidas al aislamiento, existen otras, también importantes, debidas a la proximidad: deseo de oponerse, de distinguirse, de adquirir una personalidad propia... Por consiguiente la diversidad de las culturas humanas no debe inducirnos a una observación diferenciada o dividida. Dicha diversidad se debe menos al aislamiento de los grupos que a las relaciones que los unen." (Lévi-Strauss; 1961 en Fernández de Rota, 2005: 46) 
Según Abu-Lughod esta concepción esencialista de la práctica antropológica da lugar a una ideología que distancia y encasilla el objeto de estudio, ocultando la rica diversidad cultural e induciendo a la creación de estereotipos y a la homogeneización de los "nativos". Abu-Lughod critica la instrumentalización del concepto de cultura por parte de occidente alegando que "la cultura opera en el discurso antropológico reforzando las separaciones que inevitablemente conllevan un sentimiento de jerarquía" (AbuLughod; 1991: 138). Esta relación asimétrica, jerárquica, en la que occidente surge como dominador, crea una separación entre occidente y no occidente representada en este caso bajo la figura del antropólogo viajante y su objeto de estudio encarcelado. Siguiendo esta misma línea, Appadurai afirma que esta perspectiva entraña la encarcelación de lo nativo, delimitándolo a un espacio concreto y volviéndolo también preso de su cultura. "Pero la parte fundamental de la atribución de lo nativo a grupos en lugares remotos del mundo es la sensación de que su encarcelamiento implica una dimensión moral e intelectual. Son limitados por lo que saben, sienten o creen. Son prisioneros de su modo de pensar" (Appadurai; 1988: 37).

El nativo se representa territorializado en un espacio geográfico, asociado a su cultura e incapaz de escapar de ella; al contrario, el antropólogo encarna una especie de mito romántico de viajante y aventurero. Se establece así una relación asimétrica entre occidente y no-occidente en la cual el antropólogo, representante de la elite occidental, dispone de movilidad y distinción, mientras que su objeto de estudio, el otro, lejano de occidente, es considerado "exótico", "primitivo" o menos "desarrollado"4.

7 La antropología contemporánea nos ha mostrado que no existe una cultura localizada en un espacio en concreto. Es preciso un paradigma que no piense en la cultura como una característica natural de un territorio o un estado. Esta problemática del espacio en la tarea antropológica ha sido un tema muy debatido por la Antropología en los últimos años. Precisamente, en la obra editada por Gupta y Ferguson (1997) se critica la asociación naturalizada entre territorio, ciudadanía e identidad, ya que surgen nuevos sujetos que la ponen en cuestión. Se examina la forma en la cual las representaciones asimiladas sobre el espacio han dado forma y continúan dando forma al sentido común antropológico. En ese sentido, el espacio funciona como el principio central de organización del pensamiento, el lugar desde el cual se piensa, pero el cual nunca se cuestiona. En la actualidad cada vez surgen más procesos que desafían esta naturalización entre el espacio y la cultura. Por ejemplo, las personas que viven en la frontera de los límites nacionales. Pensemos el caso de los jóvenes "de origen caboverdiano" del barrio que viven entre Francia y Portugal, ¿cuál sería su cultura? ¿La de Cabo-Verde, el país de origen de sus padres? ¿La aprendida en Francia? ¿La vivida en Portugal en las ferias de verano? ¿La que comparten en el barrio con sus amigos?

8 En los lugares en los cuales las diferencias culturales se toman en consideración dentro de una localidad o un Estado surgen conceptos como multiculturalismo y subculturas.

"El multiculturalismo es, al mismo tiempo, un débil reconocimiento del hecho de que las culturas han perdido sus amarras en sitios definidos, y un intento de someter esta pluralidad de culturas dentro del marco de una identidad nacional. De manera similar la idea de subculturas trata de preservar la idea de distintas culturas mientras que reconoce la relación de diferentes culturas hacia una cultura dominante dentro del mismo espacio geográfico y territorial" (Gupta y Ferguson; 1997: 3).

9 Estos conceptos intentan cambiar esa asociación naturalizada entre cultura y espacio, pero fallan en la forma de cuestionar esta suposición de manera verdaderamente 
absoluta. En este sentido, resulta más interesante problematizar el modelo de Estado, en este caso portugués, y pensarlo como una opción posible entre otras, pensar cómo la inmigración o el poscolonialismo lo han cuestionado en su definición de lo que es y entonces como se redefine y se replantea.

Hemos apuntado que en los últimos años se ha hablado mucho sobre la desterritorialización y la des-esencialización de la cultura, sobre la idea de romper con la asociación naturalizada entre cultura y espacio. Pero muchas veces esta concepción esencialista de la cultura se extrapola y se reproduce al pensar los movimientos sociales como si formasen un todo coherente y homogéneo. ${ }^{5}$

11 Como indica el título de este artículo, vamos a abordar el rap político en la Cova da Moura, más concretamente, la producción de sociabilidades y estilos de vida entre un grupo de jóvenes, a partir de las retóricas del rap y de los aspectos ideológicos del hip hop. El hip hop es un movimiento urbano transnacional, característico de interrelaciones cada vez más complejas y dinámicas que permiten la comunicación de las diferentes partes de una misma "comunidad imaginada" (Anderson, 1983). La dinámica cultural del hip hop constituye un proceso híbrido que despliega referencias múltiples basado en flujos culturales globales (Appadurai, 1990).

No podemos pensar en términos de "una cultura hip hop" ya que el hip hop es un movimiento cultural global y flexible. En ese sentido debemos des-esencializar este tipo de movimiento, ya que como ya hemos apuntado, la Antropología hace tiempo que ha dejado de pensar en culturas uniformes y cerradas en sí mismas. Todo grupo social es heterogéneo, y pasa por una constante redefinición, en la cual las formas de interpretar y sentir son siempre sorprendentes. Appadurai, en Modernity at large-Cultural Dimensions of Globalization, considera la cultura de forma discursiva proponiendo una visión contextual de la cultura en la cual la cultura no es propia o natural de los grupos sociales, si no algo que se expresa y se construye (Appadurai, 1996). Por eso, no pensamos que hay una identidad estructurada, una identidad cultural verdadera y definible a largo plazo detrás de este tipo de movimiento, sino una plasticidad identitaria en una dinámica relacional que "juega" con la identidad. Las relaciones que se traban entre estos jóvenes no son de identidad, sino antes de diferenciación, creación e innovación. Según Pais "las identidades son imaginadas y reinventadas en procesos constantes de hibridación cultural" (Pais; 2004: 52). Procesos que son fruto de interacciones, de identificaciones y estrategias, que dan origen a nuevas formas de ser y estar en el mundo.

El hip hop no se constituye como una forma cultural autónoma, y con fronteras definibles. Al contrario, la dinámica cultural de este movimiento constituye un proceso híbrido, consumible y manipulable en diversos modos de apropiación. En nuestro estudio de caso, en la Cova da Moura, nos aproximamos a la interpretación de la manera de interpretar el rap por un grupo de jóvenes. Para ello, nos interesamos sobretodo por el estudio de las retóricas y poéticas discursivas del rap, los aspectos ideológicos y la forma en la que influyen en la producción de sociabilidades y estilos de vida entre este grupo de jóvenes. Las retóricas del rap son muy importantes porque, por un lado, nos permiten acceder al universo conceptual de estos jóvenes y acercarnos al mundo de relaciones que se organiza y que da sentido a los conocimientos y prácticas del grupo según sus propios términos. Además, las letras de rap también dan voz a algo que ellos necesitan decir. Sus líricas adquieren un significado político, de intervención social, en una expresión reivindicativa y de protesta. En este sentido el rap representa 
una práctica de resistencia, un instrumento político de unos jóvenes que se sienten excluidos. No podemos obviar que este trabajo tiene una dimensión política, la representación del rap en la Cova da Moura da origen a algunos procesos creativos que debemos entender como políticos. Hablamos por lo tanto de cultura política, una vez que el grupo promueve sus iniciativas ideológicas a través de sus líricas y prácticas culturales.

En el contexto de la sociedad pos-colonial portuguesa, el hip hop se ha convertido en una herramienta de reflexión y autoafirmación para muchos jóvenes residentes en barrios sociales o de hábitat degradado. Debemos señalar el peso de la segregación social y racial en los espacios de hábitat degradado, ya que la mayor concentración habitacional en barrios degradados se centra entre las familias de inmigrantes más desfavorecidos en la estratificación social. Así, los barrios en los que la presencia de inmigrantes es visible, son estigmatizados como barrios de inmigrantes, dando pie a la creación de una ideología racista y de exclusión, la cual sirve para resaltar el peligro que estos barrios y sus habitantes representan para la sociedad, reproduciéndose así un recelo basado en ideas de exclusión racial y social. De esta forma, pertenecer a un barrio como la Cova da Moura implica lidiar con una serie de estereotipos y estigmas erigidos socialmente.

En este sentido, estos jóvenes representando el hip hop encuentran los materiales simbólicos e ideológicos para reinventar el lugar social en el que se sitúan, invierten los valores de cuestiones que son tratadas de forma peyorativa por el resto de la sociedad, construyendo así una identidad afirmativa y de vanguardia y convirtiendo lo que podía ser el estigma de su condición social y étnica en una bandera. No son negros y pobres sino que son niggaz y de ghetto. ${ }^{6}$

El estilo de rap que se representa en la Cova da Moura es el denominado rap consciente o rap crítico. Así, muchos de Mcs se autodenominan "MC activista" ya que acompañan su discurso de crítica social con la acción. El principal objetivo de sus letras es provocar la reflexión y crear conciencia en el público a través del mensaje que transmiten ${ }^{7}$. En este sentido nos corresponde hablar de cultura política o cultura en acción, ya que el grupo promueve sus iniciativas ideológicas a través de eventos culturales ${ }^{8}$. En sus letras critican la alienación producida por los medios de comunicación, denuncian la falta de oportunidades y empleo, la discriminación y la exclusión social, la violencia policial, el racismo, etc. A través de las letras de rap relatan su vida cotidiana, emitiendo un discurso crítico y cuestionando las formas de poder.

“A juventude já não vão nessas cantigas, já não vão nessas coisas da cultura tipo aahh ... só quero tarara ... e dar saltos ... ya, tás a ver? Agora o people ... o pessoal daqui do bairro, o pessoal que vêm do ghetto mesmo não querem, porque a mim dizem mesmo ... 'não queremos ouvir porcarias, queremos ouvir mesmo da realidade' ... tás a ver? Apesar da realidade não vender, não vender como o comercial ... mais eu não tou, não tou aqui ... e penso que ninguém que tá aqui também tá p'ra cantar ... não está aqui p'ra ganhar dinheiro ... está aqui sim p'ra sua mensagem ser ouvida, p'ra dar a conhecer nossa realidade e também p'ra mostrar que nós estamos aqui presentes p'ra mostrar o que é o verdadeiro significado do Rap, tás a ver? Intervenção ... nós não estamos aqui a brincar ..." (Kromo di Ghetto) ${ }^{9}$

De forma que el rap que representan estos jóvenes no está pensado para gustar a las discográficas, ni para ser comercial, sino que se caracteriza por el realismo de sus letras ${ }^{10}$. Luchan por otra forma de inserción social, distinta de aquella precaria y marginal que les ofrece la sociedad. Para ello, utilizan la fuerza de la palabra, y su arma 
es el rap. "Sou apenas um jovem negro, residente do subúrbio, Cova da Moura, onde a miséria e a injustiça flagela-nos diariamente. Como eu não tenho ao meu dispor os media para mostrar a sujeira desse sistema parasita e cruel, que nos mantém oprimidos, que nos atropela com a sua ganância, tenho o Rap, a minha arma contra a opressão e farei dela uma ferramenta para a revolução" (LBC) ${ }^{11}$.

Se encuentran en situación de vulnerabilidad, situados al margen de la sociedad portuguesa, sufren las contracciones del desigual sistema económico y social. La mayoría de estos jóvenes han nacido en Portugal. Pero debido a una ley que define la nacionalidad en función al origen de sus padres y no a la tierra en la cual se nace y se vive, no son considerados ni social ni jurídicamente portugueses. Los que tienen el documento de nacionalidad portuguesa lo ven más como un medio que les facilita la inserción en el mercado laboral, o poder salir a otros países de la Unión Europea que como un factor identitario ${ }^{12}$. El espacio del barrio en cambio asume una gran importancia, ya que permite una nueva mirada sobre sí mismo y un terreno común para la construcción de proyectos identitarios de diferenciación e innovación que les conceden autonomía y autoestima. Las experiencias compartidas en el barrio crean una intensa sociabilidad. Expresan la importancia del barrio, del ghetto, entre otras formas, representándolo en sus líricas o marcándoselo en la piel con tatuajes. Se refieren a la Cova da Moura como "Noz Kasa", expresión que no puede traducir mejor el sentimiento de pertenencia de estos jóvenes hacia este espacio. En este territorio encontramos características similares a las que Magnani define como "pedaço", es decir, un espacio bien delimitado en el cual interactúan densas relaciones de sociabilidad entre las personas que conviven en él (Magnani, 1984). Así, se constituye una región que comparte características definidas entre lo público y lo privado, entre la calle y la casa. A su vez, identificamos varios "micro-pedaços" o "pedacinhos" (Alvito, 1998), espacios dentro del barrio conquistados por y para los jóvenes y en los cuales se producen redes de relaciones más densas. Espacios en los cuales los jóvenes se encuentran y comparten sus experiencias y actividades, creando así una red de códigos y complicidades. En un entorno marcado por la debilidad de las instituciones oficiales, el sentimiento de pertenencia al barrio proporciona una fuerte unión entre los jóvenes del barrio.

Hablar de identidades es hablar de procesos identitarios y de diferenciación. Este fuerte sentimiento de pertenencia al barrio adquiere su significado en la necesidad de diferenciarse de los jóvenes de otros barrios con los que se relacionan. Se juega con la identidad de forma competitiva y estratégica, política. "Nós estamos a representar o Rap da Cova da Moura... ya... eu falo da Cova da Moura, porque eu sou da Cova da Moura, outro que é da Damaia, que é de Miraflores, que é de etc. ... cada um que defenda sua zona, que eu defendo a minha... como as pessoas que tão cá também defendem a causa do bairro... um bairro altamente difamado pela comunicação social" (Kromo di Ghetto) ${ }^{13}$.

20 Siguiendo la teoría de Barth en la introducción a la obra Ethnic Groups and Boundaries. The social Organization of Cultural Difference, la cual afirma que en el proceso de identificación lo primero es establecer aquello que llama de frontera, es decir, esa voluntad de marcar el límite entre "nosotros" y "ellos" (Barth, 1996). El análisis de Barth presta atención a la forma en la que los sujetos manejan los componentes culturales en la construcción de sus identidades. Ya que lo que crea la frontera, el alejamiento, es la voluntad de diferenciación, es decir, los mecanismos de interacción que utilizan la cultura o ciertos trazos culturales de modo estratégico, como 
marcadores de su identidad específica, en un proceso de identificación. De este modo, se pone atención a esos límites, a la relación de interacción entre los grupos y no al contenido que ellos encierran.

El rap representado en la Cova da Moura se conoce como rap real. Resulta en este punto muy interesante pensar en el significado de lo que se considera real, y en oposición a qué se construye esta visión de lo que es rap real.

La retórica de la autenticidad va ligada a la vida en la calle o la experiencia callejera, y a expresiones como "life in the street" y "real nigguz do real thingz". Para estos jóvenes la street, la calle, representa las vivencias que comparten en el barrio, tanto los momentos buenos como los malos. Un MC no puede hablar de ciertos temas sin haberlos vivido, ahí que la experiencia de vida en la calle asume su máxima importancia ya que legitima el discurso del MC. Pero en realidad, ¿quál es la práctica de rap correcta? Resulta sorprendente que está cuestión esté en constante discusión y debate dentro del grupo $^{14}$. La retórica de la comercialidad, se fundamenta en la diferenciación de dos polos el rap comercial y el rap underground o rap real. En este caso, es una crítica por parte de los grupos que se consideran underground a los grupos que en su opinión se unen al estilo como una estrategia de marketing comercial, e interés económico, a los que llaman suckers. Éstos, a su vez, objetarán esta etiqueta, ya que todos se quieren presentar como underground, entendiéndose como la fórmula más pura del hip hop. Según Fradique, esta dicotomía del rap comercial y el underground refleja un conflicto generacional relacionado con la entrada del rap producido en Portugal en el mercado discográfico, y consecuente profesionalización de algunos MC's de la llamada primera generación (Fradique; 1998: 128-129). Fradique sugiere acertadamente que la influencia del conflicto generacional es en gran parte debido a la influencia y la controversia por el álbum Rapublica (1994), en el cual participaron algunos de grupos que hacían rap en aquella altura, y del cual se vendieran más de quince mil copias en el primer año. De todas formas, no creemos que el conflicto generacional sea suficiente para explicar la dicotomía entre el rap comercial y el underground, ya que no existen unas características concretas y bien delimitadas que dividan los grupos como comerciales y underground. Esta distinción, al contrario, se basa en una serie de discursos que se superponen y que en ocasiones se desvanecen, unas retóricas plurales y versátiles que pasan por una constante redefinición.

Entre estos jóvenes, el peso de la reflexión sobre los acontecimientos sociales y políticos es muy importante. La problematización que realizan resulta muy productiva, de ahí el potencial creativo y perturbador del hip hop como modo de vida. Establecen una clara distinción entre el discurso de intención y la acción desarrollada en el día a día. Es decir, si un MC no acompaña sus palabras con la acción, es probable que no se le considere real. Más que representar rap, de lo que se trata es de participar de una vivencia común que se estructura en un modo de vida unido a las experiencias que se comparten en los barrios. Se me ocurre el caso de "Valete"15. Todas sus letras son de resistencia a los valores hegemónicos y muy políticas. Pero muchos de los jóvenes no lo consideran real. En cambio, en otros medios es un MC muy respetado. ¿La explicación que me dieron? Valete ha escrito una letra en oposición a la religión y a Dios. Recuerdo que un joven me dijo que él no era creyente pero que había visto que la religión había ayudado a muchos jóvenes del barrio que tenían problemas. Otro discurso en contra de este MC era que se considera superior a los demás. Mencionaban una estrofa en la que dice "sou como Malcom-X com o microfone na mão", y decían que él no había echo 
nada en su vida como para poder compararla con la de Malcolm X. Al parecer, Valete habla mucho de intervención pero no lo acompaña con la acción cotidiana, con la presencia en los barrios, por lo tanto no es real en su discurso y además no es humilde ya que se permite criticar a Dios y compararse con Malcolm X. Por lo tanto, parece que el carácter intervencionista de las letras de un MC tampoco es suficiente para considerarlo real.

Parece que estos discursos críticos sobre la comercialidad o la validez de los MC no son definidos y delimitados de una forma homogénea. Antes son manejables e inestables ya que se problematizan y pasan por una constante redefinición y debate. Precisamente estas controversias, y la organización de esta pluralidad de discursos, las contradicciones, estrategias e improvisaciones, son las que vuelven tan interesante y heterogéneo este grupo social ${ }^{16}$.

"A cultura hip hop quando começou aqui mesmo era visto como cultura marginal, e quando começou a ganhar terreno, muitos viram que aquilo dava dinheiro e começou a aparecer aquelas editoras... e logo os niggas mesmo, a ganhar com isso, $\mathrm{e}$ agora, querem tirar-nos mesmo o que é nosso... e hip hop cá na tuga é dos africanos mesmo... os africanos é que começaram e agora falam de hip hop e falam de... idiotas de grupos comerciais... A música deles não tem alma... é comédia... nós falamos da realidade e eles querem fazer o povo esquecer da realidade !!! Eles querem tirar o percurso do hip hop" (Nigga Djurra, MC Faruq, Jakilson) ${ }^{17}$.

En el fragmento de la entrevista de arriba, MC Faruq dice que "el hip hop en Portugal es de los africanos". Muchas veces los propios actores sociales caen en el propio discurso predefinido. Esta retórica de reivindicación de las raíces africanas ha sido muy difundida, tanto en el discurso social como en el académico, de hecho, forma parte de las narrativas míticas del origen de esta auto-denominada cultura hip hop. En ese sentido, no podemos obviar estas narrativas ya que esos discursos que han mitificado el rap forman parte de él. ${ }^{18}$

Fradique apunta a una rapificación y racialización del hip hop como consecuencia del proceso de mercantilización. Así, el rap no solamente pasa a representar el lado más visible y consumible de esta cultura, como también a ser definido como la más contemporánea expresión de la (supuestamente homogénea) cultura negra (Fradique, 1998:59).

Con la racialización del estilo, la autora quiere hacer hincapié que en Portugal se ha vendido el rap como el lenguaje cultural del otro, el lenguaje cultural de los hijos de inmigrantes negros que viven en la periferia de Lisboa. Este dato es muy significativo ya que la comprensión del significado que estos jóvenes dan al movimiento hip hop consiste en entender cómo ellos "juegan" con imágenes de ellos mismos, imágenes o retratos creados por otros sobre ellos (los medios de comunicación tienen un papel muy relevante) y que ellos quieren mantener y reproducir, porque de eso entienden que vive el rap.

28 En realidad, hay otros componentes que son mucho más relevantes que el origen étnico, entre otros, el componente territorial, el compartir un conjunto de experiencias relacionadas con la calle, con el barrio, con el rap, el compartir códigos de comportamiento y hábitos de consumo cultural. El compartir la misma condición social y por tanto, las mismas dificultades para entrar en el mercado de trabajo, etc. En varias ocasiones se menciona la poca identificación que sienten con la escuela en Portugal, en la cual sienten que no están representados o que se les discrimina. 
"Na escola portuguesa nós somos vistos como "cobaias», como ratos de laboratório... a parte da história aonde aparecemos é só como escravos... e também nossos países aparecem como os países que eles foram la com a expedição marítima... sempre como inferiores... nós temos mesmo uma história... mas não falam disso... de Nelson Mandela, por exemplo... Eu vi muitos mesmo... vi muitos mesmo acabarem de desistir da escola... não têm vontade de ir para a escola... Porque sabem o que as escolas lhes mostram... é que eles mesmo... os que estão lá... são inferiores... a escola não mostra... que eles têm a cultura deles, que é diferente... a cultura africana é vista como ridícula mesmo... para eles é ridícula... os nossos hábitos de cultura são ridicularizados..."19 (Jakilson)

La inconmensurabilidad de los procesos de globalización, nos transmiten una imagen de globalidad e uniformidad. El trabajo de campo nos permite atravesar esta fachada y encontrar resistencias y reinterpretaciones y acompañar una pluralidad en cambio continuo. Así se rechaza la ilusión de la homogeneidad de la "cultura", de la "etnia", del "grupo de jóvenes" y del propio "rap". De forma que, retomando la idea inicial del texto, al contrario de lo que pensábamos en un principio, el hip hop no se constituye como una forma cultural autónoma y compacta. Al contrario, la representación del rap crítico o de consciencia en la Cova da Moura se trata de una expresión heterogénea y dinámica fruto de los acontecimientos e interacciones de cada individuo. Esta apropiación dinámica del hip hop, a su vez, es el reflejo de un proceso identitario múltiple. Por lo tanto, pensar estos jóvenes bajo el punto de vista identitario significa pensar en identidades múltiples y en su multicreatividad, en formas de diferenciación, creación e innovación y en el potencial creativo y de intervención del hip hop.

\section{BIBLIOGRAFIA}

ABU-LUGHOD, L. (1991), "Writing Against Culture”, in R. G. Fox (Ed.), Recapturing Anthropology, Santa Fé, School of American Research Press, pp. 137-161.

ALVITO, M. (1998), "Um bicho de sete cabeças" in Um século de Favela, Rio de Janeiro, Fundação Getúlio Vargas, pp. 181-208.

ANDERSON, B. (1991) (1983), Imagined communities, London, Verso.

APPADURAI, A. (1996), Modernity at Large-Cultural Dimensions of Globalization, Minneapolis, University of Minesota Press.

APPADURAI, A. (1990), "Disjuncture and Difference in the Global Cultural Economy", Public Culture, 2, pp. 1-24

APPADURAI, A. (1988), "Putting Hierarchy in Its Place", Cultural Anthropology, 3 (1), Place and Voice in Anthropological Theory, pp. 36-49.

BARTH, F. (1976) [1969], Los Grupos Étnicos y sus Fronteras, México, Fondo de Cultura Económica.

FERNÁNDEZ DE ROTA, A. (2008), “Sistema nervioso, contra-reciclaje y piratería: Una etnografíamanifiesto", Revista de Antropología Experimental, Universidad de Jaen, 8 (27), pp. 365-396.

FERNÁNDEZ DE ROTA, J. A. (2005), Nacionalismo, Cultura y Tradición, Barcelona, Anthropos. 
FRADIQUE, T. (1998), "Culture is in the House": O Rap em Portugal, a Retórica da Tolerância e as Politicas de Definição de Produtos Culturais, Dissertação de Mestrado, Lisboa, Departamento de Antropologia. ISCTE.

GEERTZ, C. (2005), La interpretación de las culturas, Barcelona, Gedisa.

GUPTA, A. e J. Ferguson (1997), "Más allá de la «cultura": Espacio, identidad, y la política de la diferencia" Culture, Power, Place, Duke University Press.

HANNERZ, U. (1998), Conexiones Transnacionales: Cultura, Gente, Lugares. Madrid, Cátedra. Traducción: María Gomis.

MAGNANI, J. G. (1984), Festa no Pedaço: cultura popular e lazer na cidade, São Paulo, Brasiliense.

PAIS, J. M. (2004), “Jovens, bandas musicais e revivalismos tribais” in Tribos Urbanas. Produção artística de identidades, Lisboa, Impresa de Ciências Sociais, pp. 23-55.

\section{NOTAS}

1. Me gustaría agradecer a todas las personas del barrio de la Cova da Moura por su hospitalidad, amistad y cariño y especialmente a los MCs por ser grandes MCs pero lo que es más importante grandes personas.

2. Barrio del consejo de Amadora, área metropolitana de Lisboa. Surgió en 1960, pero fue a partir de 1974 que se dio una ocupación más intensa y continua. Las propias familias construyeron la mayoría de las casas, basándose en un sistema de entreayuda, djunta mon, o "juntar las manos”. Los habitantes eran en su mayoría portugueses retornados de las ex colonias y los inmigrantes que venían de África, principalmente caboverdianos.

3. La música Rap (Rhythm And Poetry) forma parte de la autodenominada cultura hip hop. El Rap, Dj, Break Dance y el Graffiti, representan la voz, la música, la danza y la pintura en el hip hop.

4. Actualmente, observamos el reflejo de esta encarcelación, cuando en el imaginario social los descendientes de emigrantes son constantemente asociados a su cultura de origen, la cual se localiza en un lugar distinto y lejano del que residen. La construcción de la imagen acerca del inmigrante deriva además de varios otros factores. Entre otros, cabe resaltar que el papel de los medios de comunicación es decisivo en la definición de esta imagen.

5. Nos unimos aquí a la crítica de Antón Fernandez de Rota en "Sistema nervioso, contra-reciclaje y piratería: Una etnografía-manifiesto" (2008:368) quien refiere que los estudiosos de los movimientos sociales cometen el error de hablar de "la cultura okupa" en singular.

6. Se positiviza la identidad de negro nigga, es decir, no blanco, no la mayoría, no occidental, etc. y de ghetto, el espacio de exclusión socio-económica y racial de los inmigrantes.

7. En lo que respecta a la valorización de las cualidades de un buen MC, apreciamos dos vertientes, lo que más se valora es el mensaje que se transmite pero también reconocen la importancia del flow, el estilo rítmico del MC.

8. Agradezco la idea de "la cultura en acción" a las reuniones del grupo de investigación del profesor José Antonio Fernández de Rota, “Análisis Antropológico de la Cultura en Acción de los Nuevos Movimientos Sociales".

9. "La juventud ya no va en esas cantinas, ya no va en esas cosas de la cultura tipo sólo quiero lalala... y dar saltos ¿entiendes? Ahora el people, el personal de aquí del barrio, el personal que viene del gueto mismo no quieren, porque a mi me lo dicen 'no queremos escuchar porquerías, queremos escuchar mismo de la realidad' ¿entiendes? A pesar de que la realidad no venda, no venda tanto como lo comercial, pero yo no estoy aquí, y pienso que nadie lo está, no estamos aquí 
para ganar dinero, estamos aquí para que nuestro mensaje sea escuchado, para dar a conocer nuestra realidad y también para mostrar que nosotros estamos aquí presentes para mostrar lo que es el verdadero significado del Rap, ¿entiendes? Intervención, nosotros no estamos jugando..."

10. En la actualidad poseen un estudio de grabación en el espacio joven de la asociación Moinho da Junventude del barrio.

11. "Soy apenas un joven negro, residente del suburbio, Cova da Moura, donde la miseria y la injusticia nos flagela diariamente. Como yo no tengo a mi disposición los media para mostrar la suciedad de este sistema separatista y cruel, que nos mantiene oprimidos, que nos atropella con su ganancia, tengo el Rap, mi arma contra la opresión y haré de ella una herramienta para la revolución."

12. Al ser preguntados por su nacionalidad y si responden que son portugueses les vuelven a preguntar en seguida “¿si pero de dónde?” debido al color de su piel.

13. "Nosotros estamos representando el Rap de la Cova da Moura, yo hablo de la Cova da Moura, porque yo soy de la Cova da Moura, otro que es de Damaia, que es de Miraflores, que es de etc. cada uno que defienda su zona, que yo defiendo la mía. Como las personas que están aquí también defienden la causa del barrio... un barrio altamente difamado por la comunicación social"

14. En una ocasión asistimos a un debate organizado en el barrio, al cual asistieron varios Mcs de otros barrios que también rimaban en Kriolo (lengua originaria de Cabo Verde), y en el que se debatió y problematizó cómo se debería llamar "rap kriolo" o "rap en kriolo".

15. MC portugués hijo de emigrantes africanos. (http://www.myspace.com/valete115)

16. De todas formas estas controversias sobre la comercialidad y no comercialidad del estilo en este movimiento no son nuevas, al contrario, son discusiones usuales siempre que un fenómeno cultural marginal irrumpe en el mainstream (el samba, el jazz etc.).

17. "La cultura hip hop cuando comenzó aquí mismo era visto como cultura marginal, y cuando comenzó a ganar terreno, muchos vieron que aquello daba dinero y comenzaron a aparecer aquellas editoras y luego los niggas mismo, a ganar con eso, y ahora, quieren quitarnos mismo lo que es nuestro... el hip hop aquí en Portugal es de los africanos... los africanos son quienes comenzaron y ahora hablan de hip hop y hablan de... idiotas de grupos comerciales... A música de ellos no tiene alma... es comedia... nosotros hablamos de la realidad y ellos quieren hacer al pueblo olvidar de la realidad. Ellos quieren acabar con el percurso del hip hop."

18. Los primeros trabajos sobre el rap (Toop; 1994; Dufresne, 1991; Rose, 1994; Fernando, 1994; Keyes, 1996), son obras que recogen sobretodo registros descriptivos y fotográficos, pero independientemente de la validez científica que queramos asignar a estas obras, tenemos que tener en cuenta que son muy importantes ya que constituyen las narrativas de historización de la música rap.

19. En la escuela portuguesa nosotros somos vistos como "cobayas" como ratas de laboratorio, la parte de la historia donde aparecemos es sólo como esclavos, y también nuestros países aparecen como los países a los que ellos fueron con la expedición marítima. Siempre como inferiores, nosotros también tenemos una historia pero no hablan de eso, de Nelson Mandela por ejemplo. Yo vi muchos que acabaron desistiendo de la escuela, que no tenían ganas de ir a la escuela porque saben lo que la escuela les muestra, es que ellos son inferiores, la escuela no enseña que ellos tienen una cultura, la cultura africana es vista como ridícula, para ellos es ridícula y nuestros hábitos de cultura son ridiculizados 


\section{RESUMOS}

Partiendo de una reflexión de los conceptos de cultura y de política, y de las relaciones entre ambos, la presente propuesta de comunicación pretende abordar un estudio de caso sobre la producción de sociabilidades y estilos de vida entre un grupo de jóvenes en la Cova da Moura (Lisboa) a partir de las retóricas del rap y de los aspectos ideológicos del hip hop.

Para este grupo, el espacio del barrio asume una gran importancia, constituyendo el terreno común para la construcción de proyectos identitarios que les conceden autonomía y autoestima. Al mismo tiempo, sus experiencias compartidas en el barrio crean una intensa sociabilidad.

El hip hop es un movimiento cultural global flexible y manipulable en diversos procesos de apropiación. En la Cova da Moura la representación del rap da origen a algunos procesos que debemos entender como políticos. Parece pertinente, por lo tanto, hablar de cultura política, una vez que el grupo promueve sus iniciativas ideológicas a través de sus líricas y eventos culturales.

Starting from a reflection of the concepts of culture and politics, and relations amongst them, this paper aims to discuss a case study on the production of sociability and lifestyles among a group of young people in the Cova da Moura (Lisbon) from the rhetoric of rap and ideological aspects of hip hop.

For this group the area of the district assumes great importance, because it is a common base for the construction of processes of identities and differentiation, providing autonomy and selfesteem, as well as the experiences shared in the district create an intense sociability.

The hip hop is a global and flexible cultural movement manipulate in different processes of appropriation. The representation of rap in Cova da Moura results in some cases which we must understand as politicians. It seems appropriate to speak of political culture because of the group promotes its activities and ideological position through its lyrics and cultural events.

\section{ÍNDICE}

Keywords: new political and social movements, political culture, rhetoric of rap

Palabras claves: nuevos movimientos políticos y sociales, cultura política, retóricas del rap

\section{AUTOR}

\section{EDURNE DE JUAN}

Universitat de Barcelona

enune3@hotmail.com 